\title{
Optimisation of the preparation of a phosphomagnesium cement based on struvite and K-struvite
}

\author{
H. Hammi, and A. Mnif \\ Laboratoire de Valorisation des Matériaux Utiles, Centre National de Recherches en Sciences des Matériaux, Technopole \\ Borj Cedria, Soliman, Tunisie
}

Cement is the most widely used material in construction. Its properties are crucial for construction quality. The commonly used cement is Portland cement, which since its discovery in 1812, has continued to be developed in order to improve their properties. Other types of cement have made their appearance due to a coincidence or a result of targeted research. In fact, every era has its obligations and researchers work to guarantee them. For special applications, we are called to respond to demands for speed, efficiency and sustainability. This applies to the repair areas with high traffic, such as roads, airports and industrial flooring. This would require a material that provides these benefits simultaneously.

Research has been oriented in this direction and have led to the discovery of phosphomagnesium cement which offers many other advantages, including resistance to aggressive media chemically and thermally, and low cost of manufacture.

In this work, we tried to optimize the synthesis of a phosphomagnesium cement having good mechanical strength. On the other hand we tried to minimize the cost of producing the magnesium oxide wich is the major component of this cement from a natural brine located at Sebkha el Melah of Zarzis. To achieve these objectives, we applied the experimental design methodology to determine the optimum synthesis of a phosphomagnesium mortar with low setting time and high mechanical strength. This study also includes the application of retardants to increase the setting time. The two types of cement obtained respectively are mainly composed of struvite $\left(\mathrm{NH}_{4} \mathrm{MgPO}_{4} \cdot 6 \mathrm{H}_{2} \mathrm{O}\right)$ or $\mathrm{K}$ struvite $\left(\mathrm{KMgPO}_{4} \cdot 6 \mathrm{H}_{2} \mathrm{O}\right)$. 